\title{
The effect of devitalized trabecular bone on the formation of osteochondral tissue-engineered constructs
}

\author{
Eric G. Lima ${ }^{\mathrm{a}, \mathrm{d}}$, Pen-hsiu Grace Chao ${ }^{\mathrm{b}}$, Gerard A. Ateshian ${ }^{\mathrm{a}, \mathrm{e}}$, B. Sonny Bal ${ }^{\mathrm{c}}$, James L. Cook ${ }^{\mathrm{c}}$, \\ Gordana Vunjak-Novakovic ${ }^{a}$, Clark T. Hung ${ }^{\mathrm{a}, *}$ \\ ${ }^{a}$ Department of Biomedical Engineering, Columbia University, 351 Engineering Terrace MC8904, 1210 Amsterdam Avenue, New York, NY 10027, United States \\ ${ }^{\mathrm{b}}$ Institute of Biomedical Engineering, National Taiwan University, Taipei, Taiwan \\ ${ }^{\mathrm{c}}$ Comparative Orthopaedic Laboratory, University of Missouri, Columbia, MO, United States \\ ${ }^{\mathrm{d}}$ Materials Characterization Laboratory, Cooper Union, 51 Astor Place, New York NY, 10003, United States \\ ${ }^{\mathrm{e}}$ Department of Mechanical Engineering, Columbia University, Department of Mechanical Engineering, 500 West 120 th Street, Mail Code 4703,220 S.W. Mudd
}

\section{A R T I C L E I N F O}

\section{Article history:}

Received 30 April 2008

Accepted 9 July 2008

Available online 20 August 2008

\section{Keywords:}

Cartilage tissue-engineering

Biocompatibility

Bone

\begin{abstract}
A B S T R A C T
In the current study, evidence is presented demonstrating that devitalized trabecular bone has an inhibitory effect on in vitro chondral tissue development when used as a base material for the tissueengineering of osteochondral constructs for cartilage repair. Chondrocyte-seeded agarose hydrogel constructs were cultured alone or attached to an underlying bony base in a chemically defined medium formulation that has been shown to yield engineered cartilaginous tissue with native Young's modulus $\left(E_{\mathrm{Y}}\right)$ and glycosaminoglycan (GAG) content. By day 42 in culture the incorporation of a bony base significantly reduced these properties $\left(E_{\mathrm{Y}}=87 \pm 12 \mathrm{kPa}, \mathrm{GAG}=1.9 \pm 0.8 \% \mathrm{ww}\right)$ compared to the gel-alone group $\left(E_{\mathrm{Y}}=642 \pm 97 \mathrm{kPa}, \mathrm{GAG}=4.6 \pm 1.4 \% \mathrm{ww}\right)$. Similarly, the mechanical and biochemical properties of chondrocyte-seeded agarose constructs were inhibited when co-cultured adjacent to bone (unattached), suggesting that soluble factors rather than direct cell-bone interactions mediate the chondro-inhibitory bone effects. Altering the method of bone preparation, including demineralization, or the timing of bone introduction in co-culture did not ameliorate the effects. In contrast, osteochondral constructs with native cartilage properties $\left(E_{\mathrm{Y}}=730 \pm 65 \mathrm{kPa}, \mathrm{GAG}=5.2 \pm 0.9 \% \mathrm{wW}\right)$ were achieved when a porous tantalum metal base material was adopted instead of bone. This work suggests that devitalized bone may not be a suitable substrate for long-term cultivation of osteochondral grafts.
\end{abstract}

(c) 2008 Elsevier Ltd. All rights reserved.

\section{Introduction}

Articular cartilage is a specialized connective tissue that bears load and reduces friction across moving joints. It is composed of an extracellular matrix that contains no nerves or blood vessels and relatively few cells ( $5 \%$ volume). When damaged, articular cartilage does not heal, but instead often degenerates further, leading to pain and loss of function [1]. Due to the prevalence of osteoarthritis (OA) and damage to articular cartilage, coupled with this poor intrinsic healing response, there is a great demand for clinical intervention, usually in the form of a highly invasive non-biological prosthetic (such as total joint arthroplasty). Currently, the most common biological alternative to arthroplasty entails the transplantation of healthy osteochondral autografts (cartilage along with some of the underlying bone) from a non-load bearing region to the affected site [1-5]. Osteochondral grafts are better anchored than chondral-

\footnotetext{
* Corresponding author.

E-mail address: cth6@columbia.edu (C.T. Hung).
}

only grafts and are less likely to be displaced by shearing forces within the joint. While these autologous grafting procedures are promising, they are limited both by the amount of tissue available and donor-site morbidity associated with its harvest. Tissue-engineering strategies, if successful, would alleviate these problems by creating replacement tissues of the proper size and shape without concurrent damage to other regions of the patient's body.

Osteochondral constructs are designed to be press-fit into predrilled cavities in the damaged joint, replacing the host cartilage above while anchoring to the bone below. There are a great variety of tissue-engineering approaches to form osteochondral constructs, but typically they all entail the use of some form of tissue-scaffold.

The most important characteristics of the scaffold are its mechanical properties, its porosity, and its biocompatibility. Specifically it must be able to properly bear and transfer loads to the surrounding tissue without being crushed. Since this environment also includes shear forces, the interface strength between the cartilage and bone regions should also be considered. The scaffolds must also have the proper porosity to allow for cell infiltration and nutrient transport and be biocompatible to mitigate immunogenic 
issues while allowing engineered tissue to develop functional properties. The two regions of an osteochondral construct can be formed from a single continuous scaffold [6-8] or from two independent scaffolds that have been joined together [9] with each region specialized to promote chondrogenic or osteogenic development.

Although this development process would ideally take place entirely within the defect site [10-15], there is evidence that some in vitro pre-culture may be necessary to have enough fortitude to survive the harsh mix of inflammatory cytokines and concentrated loads that are common in an injured joint $[16,17]$. The amount of time dedicated to in vitro pre-culture must be considered in the choice of engineered scaffolds, especially if the scaffold material is designed to degrade over time. We have recently developed a tissue culture protocol using chondrocyte-seeded agarose hydrogel and the temporal addition of growth factors that yields engineered tissue with native Young's modulus $\left(E_{Y}\right)$ and glycosaminoglycan (GAG) content [18]. In Study 1 of the current set of experiments we expand this system to include osteochondral constructs formed using a devitalized trabecular bone as a base scaffold.

Among its many benefits, trabecular bone represents the gold standard in terms of mechanical properties, and unlike degradable substrates these properties do not change substantially over time in culture, allowing for extensive in vitro cultivation. Bone also has an interconnected porosity that is ideal for gelling chondrocyte-laden agarose or other hydrogels. It is abundantly available for research use and easily machined into a multitude of forms. Devitalized and demineralized bone is already approved by the FDA for clinical use as a scaffold to promote bone growth, as a source of osteoinductive factors, and as allografts [19]. As such it is an alluring choice for an osteochondral scaffold, however, the results of preliminary trials [20] using devitalized trabecular bone suggest there are unanticipated inhibitory effects on chondral development.
Study 1 extends these preliminary results, by examining the effect of trabecular bone on chondral development when used both directly in the formation of multi-phase osteochondral constructs and indirectly when included in the culture medium unattached to the developing gels.

An alternate approach to forming osteochondral constructs is to culture the two phases separately and join them together after certain engineering milestones have been met (i.e., mechanical or chemical fortitude, etc.). Study 2 was designed to examine the feasibility of this approach by delaying the introduction of bone to the culture medium to allow for matrix development. Finally, in Study 3 we examine porous tantalum metal, a highly promising synthetic alternative to bone, as a tissue-engineering scaffold for the formation of osteochondral constructs with functional mechanical properties.

\section{Materials and methods}

\subsection{Experimental design}

Three studies were carried out in this manuscript (Fig. 1). In Study 1 the development of chondrocyte-seeded agarose hydrogel constructs (Study 1, Gel) and osteochondral constructs (Study 1, OC(bone)) were directly compared using the same tissue-engineering protocol. To assess the effects of soluble factors released by bone, Gel constructs were also co-cultured adjacent (but unattached) to devitalized bone (Study 1, Co-culture(bone)). To exclude the effect of soluble minerals Gel constructs were also cultured adjacent to demineralized bone (Study 1, Co-culture(demin)). Finally, to test for the possibility that the inhibitory effect of bone is not related to soluble factors, but rather due to a decrease in the availability of growth factors through the absorption into bone, Gel constructs were cultured in medium without TGF- $\beta 3$ (Study 1, No TGF)

In Study 2 the possibility of forming functional osteochondral constructs after separate cultivation of the chondral region was examined by delaying the introduction of bone to day 14 of culture (Study 2, Bone Introduced on day 14) or on day 28 (Study 2, Bone Introduced on day 28). Gel constructs without any Bone Introduced served as controls (Study 2, No Bone Introduced).

\section{Study 1: Trabecular Bone is Examined as a Substrate for Osteochondral Tissue Engineering (But is Found to} Release Soluble Factors that Inhibit Chondral Development)

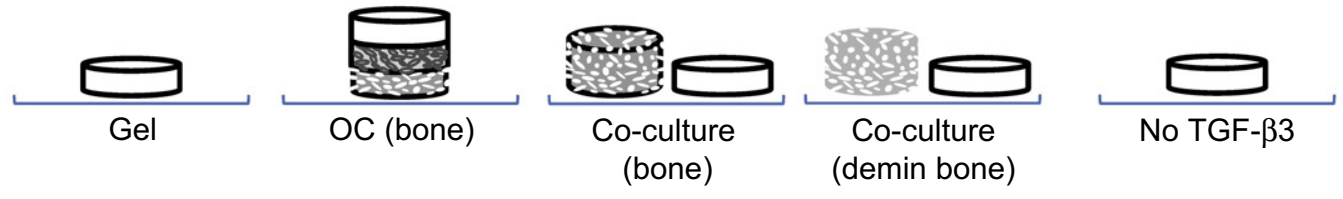

Study 2: The Introduction of Bone is Delayed to Allow for Matrix Development

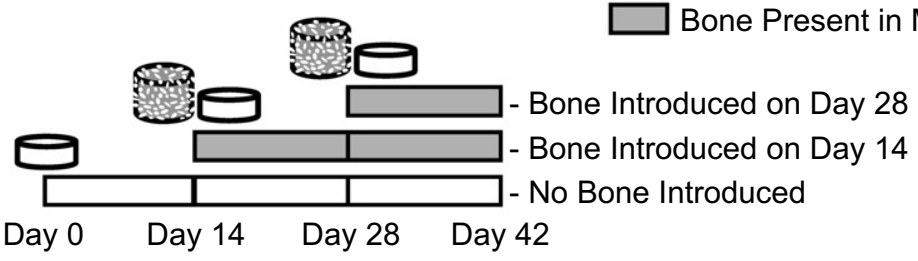

No Bone Present in Medium

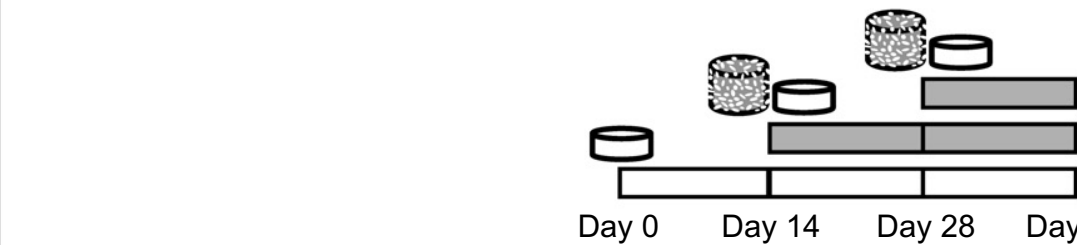

Study 3: Porous Tantalum Metal is Examined as an Alternate Substrate for Osteochondral Tissue Engineering

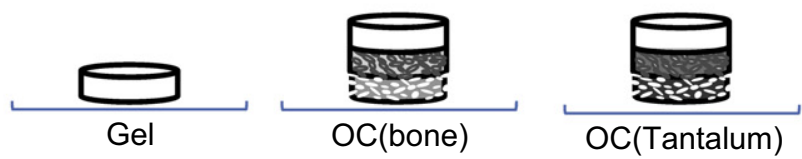

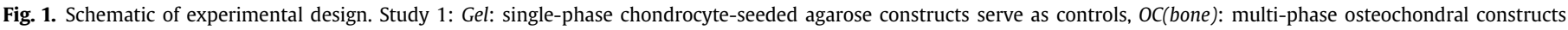

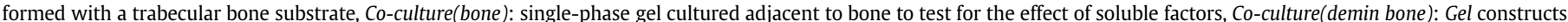

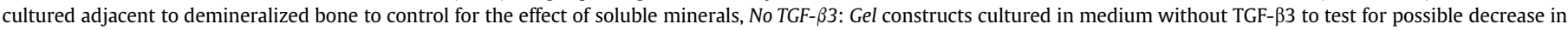

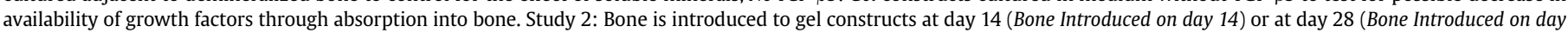

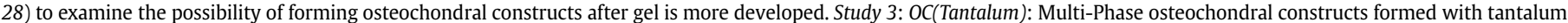
substrate, $\mathrm{Gel}$ and $O C$ (bone) serve as controls. Each study was carried out separately and all groups were cultured for 42 days. 
In Study 3 multi-phase osteochondral constructs are formed with a porous tantalum metal substrate (Study 3, OC(tantalum)) and compared to both $\mathrm{Gel}$ and $O C$ (bone) constructs. Porous tantalum metal is a non-biological substrate currently being investigated as a component for total joint arthroplasty and has shown excellent early clinical results [21-26]. Each study was carried out separately and all groups were cultured for 42 days.

\subsection{Cell isolation}

Articular cartilage was harvested from bovine carpo-metacarpal (CMC) joints of freshly slaughtered 1-3 weeks old calves. Three to five joints were used for each study and cells were pooled from all joints. Cartilage chunks were digested in highglucose Dulbecco's Modified Eagle's Medium (hgDMEM) supplemented with 5\% fetal bovine serum and $390 \mathrm{U} / \mathrm{ml}$ collagenase type VI (Sigma Chemicals, St. Louis, MO) for $11 \mathrm{~h}$ at $37^{\circ} \mathrm{C}$ with stirring. The resulting cell suspension was then filtered through a $70 \mu \mathrm{m}$ pore-size mesh and sedimented in a bench top centrifuge for $10 \mathrm{~min}$ at $1000 \mathrm{~g}$. Viable cells were counted using a hemacytometer and trypan blue.

\subsection{Osteochondral substrate preparation}

\subsubsection{Devitalized bone}

Cylindrical cores ( $\sim 15 \mathrm{~mm}$ long) of trabecular bone were isolated from the subchondral region of bovine tibia using a diamond-tipped, hollow drill (Starlite, Rosemont, PA). Cores were rough cut to $\sim 6 \mathrm{~mm}$ in length and centered in a custom $4 \mathrm{~mm}$ thick stainless steel mold such that there were overhanging surfaces on both sides of the mold. These surfaces were then sanded flat with a hand-held device to ensure that the final bone cores had uniform dimensions $(\varnothing 4 \times 4 \mathrm{~mm} \pm 50 \mu \mathrm{m})$ with parallel faces cut normal to the axis of symmetry. Bone cores were then cleaned of marrow in one of the three ways: (1) with a water pick and subsequently sterilized in $70 \%$ ethanol for $4 \mathrm{~h},(2)$ by washing in hypotonic buffer with detergent and DNAse and RNAse solutions, or (3) as provided by a commercial vendor through their FDA approved BioCleanse processes (RTI Biologics). To keep the quantity of bone consistent between experiments, cleansed bone was sorted to within a $10 \%$ deviation in mass and volume. The experiments presented in Study 1 and Study 2 were repeated with each of these cleaning methods with no significant differences in results. The data presented here are averaged across all experiments. For the Coculture(demin) group in Study 1 bone was demineralized in $6 \mathrm{~N} \mathrm{HCl}$ for $12 \mathrm{~h}$

\subsubsection{Tantalum metal}

Porous tantalum metal (Zimmer) was prepared using wire cut electron discharge machining (to maintain the scaffold porosity [27]) to final construct dimensions of $\emptyset 4 \times 4 \mathrm{~mm}$.

\subsection{Casting of chondral or osteochondral constructs}

One volume of chondrocyte suspension (at $60 \times 10^{6}$ cells $/ \mathrm{ml}$ ) was then mixed with an equal volume of $4 \%$ low-melt agarose (Type VII, Sigma) at $37^{\circ} \mathrm{C}$ to yield a final cell concentration of $30 \times 10^{6}$ cells $/ \mathrm{ml}$ in $2 \%$ agarose. For $\mathrm{Gel}$ specimens the chondrocyte/agarose suspension was cast into slabs and cored using a sterile disposable punch (Miltex, York, PA) to final dimensions (Ø $4 \mathrm{~mm} \times 2.3 \mathrm{~mm}$ ).

For osteochondral specimens $60 \mu \mathrm{l}$ of molten cell-laden agarose suspension was poured into the cylindrical wells of a custom mold. Osteochondral substrates were pressed into the gel from above to the desired depth (adjusted through a temporary retaining ring). With this technique a multi-layered construct was formed with the following dimensions: a $2 \mathrm{~mm}$ agarose-only top region, a $2 \mathrm{~mm}$ agarose + substrate interface region, and a $2 \mathrm{~mm}$ substrate-only region.

\subsection{Growth medium}

The growth medium was changed every other day and consisted of hgDMEM with $1 \times$ PSF (100 units/ml Penicillin, $100 \mu \mathrm{g} / \mathrm{ml}$ Streptomycin, $0.25 \mu \mathrm{g} / \mathrm{ml}$ Fungizone), $0.1 \mu \mathrm{m}$ dexamethasone, $50 \mu \mathrm{g} / \mathrm{ml}$ ascorbate 2 -phosphate, $40 \mu \mathrm{g} / \mathrm{ml}$ L-proline, $100 \mu \mathrm{g} / \mathrm{ml}$ sodium pyruvate, and $1 \times$ ITS + premix (insulin, human transferrin, and selenous acid, Becton Dickinson, Franklin Lakes, NJ). Chemically defined medium
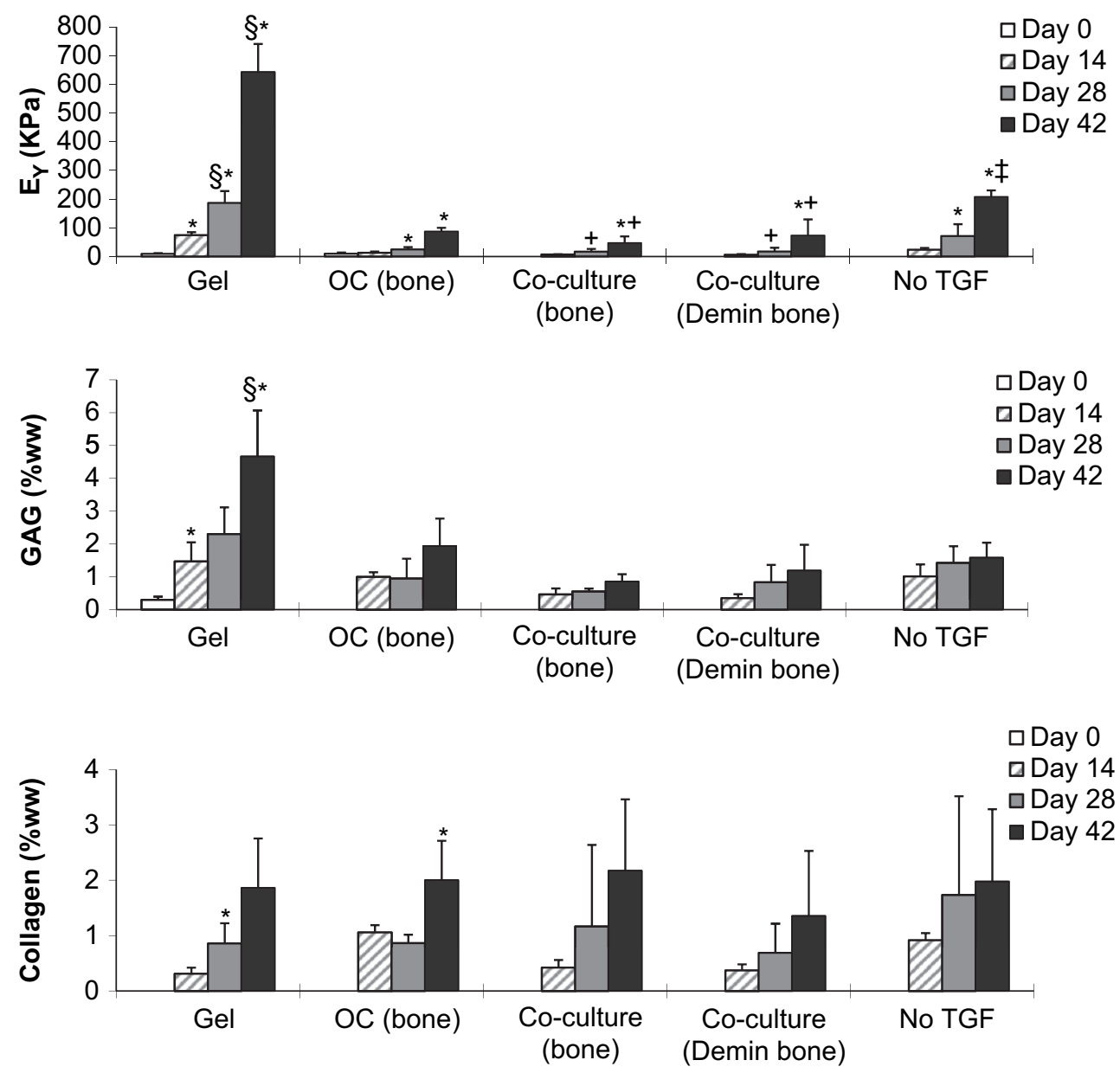

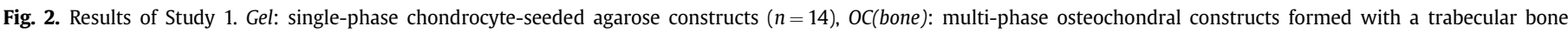

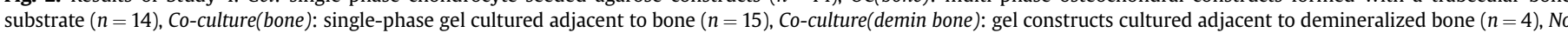

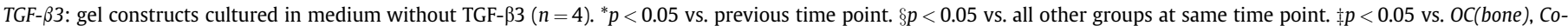
culture(demin), or Co-culture(bone). $+p<0.05$ vs. No TGF. 
was further supplemented with $10 \mathrm{ng} / \mathrm{ml}$ of transforming growth factor beta 3 (TGF$\beta 3$, R\&D Systems, Minneapolis, MN) for the first 14 days of culture.

\subsection{Material testing}

The equilibrium Young's modulus $\left(E_{Y}\right)$ is commonly used as a measure of the behavior of cartilage that has been allowed to reach equilibrium after a known load or displacement has been applied. Constructs were tested for $E_{\mathrm{Y}}$ in unconfined compression using a custom computer-controlled testing system [28]. An initia $0.02 \mathrm{~N}$ tare load was applied, followed by a compression to $10 \%$ strain (of the chondral region) at a strain rate of $0.05 \% / \mathrm{s}$. EY was calculated from the equilibrium stress at $10 \%$ strain. Previous studies have shown $E_{Y}$ to remain invariant across strain magnitudes ranging from 0 to $20 \%$ [18].

To determine the shear strength at the interface, the gel region of osteochondra constructs was cut in half, and mounted in a custom mold as to allow a platen to come into contact with the newly created flat surface (Fig. 6A). A linear displacement $(10 \mu \mathrm{m} / \mathrm{s})$ was then applied and the load measured. The shear strength at the interface was calculated in three ways, as is commonly expressed in the literature $[29,30]$. Peak load was determined as the highest force before failure (Fig. 6B asterisks). Shear stiffness was determined by curve fitting the linear region on the force/displacement curve (Fig. 6B, bold line), Energy to Failure was determined by integrating the area under the force/displacement curve to the peak load and normalizing by interface area (Fig. 6B, shaded area)

\subsection{Biochemical content}

The biochemical content of each sample was assessed by first measuring sample wet weight, lyophilizing for $24 \mathrm{~h}$, and then measuring the sample dry weight. Once dry, the samples were digested in proteinase- $\mathrm{K}$ overnight at $56^{\circ} \mathrm{C}$, as described previously [31]. Aliquots of digest were analyzed for glycosaminoglycan (GAG) content using the 1,9-dimethylmethylene blue dye-binding assay [32]. A further aliquot was acid hydrolyzed in $12 \mathrm{~N} \mathrm{HCl}$ at $110^{\circ} \mathrm{C}$ for $16 \mathrm{~h}$, dried over $\mathrm{NaOH}$, and resuspended in assay buffer [31]. Ortho-hydroxyproline (OHP) content was then determined via a colorimetric assay by reaction with chloramine $\mathrm{T}$ and dimethylaminobenzaldehyde [33]. OHP content was converted to total collagen content using the conversion of 1:10 ratio of OHP:collagen [34]. Each biochemical constituent (GAG and collagen) was normalized to tissue wet weight.

\subsection{Histological analysis}

Gel samples were fixed in acid formalin ethanol [35], paraffin embedded, sectioned ( $8 \mu \mathrm{m}$ thick), and stained to view proteoglycan or total collagen or type II collagen distribution as described previously [36]. For osteochondral constructs histological specimens were prepared through plastic embedding and stained the
Department of Surgical Sciences, University of Wisconsin. Live/dead assays were carried out using manufacture's protocol (Molecular Probes).

\subsection{Statistics}

Statistics were performed with the Statistica (Statsoft, Tulsa, OK) software package. Each data point represents the mean and standard deviation. Groups were examined for significant differences by analysis of variance $(\alpha=0.05)$, with $E_{Y}$, GAG, or OHP as the dependent variable using Tukey's Honest Significant Difference Test (HSD).

\section{Results}

\subsection{Study 1: comparing the development of chondral and} osteochondral constructs in the presence of devitalized trabecular bone

In Study 1, both osteochondral (OC(bone)) and chondral (Gel) constructs developed significantly better mechanical and biochemical properties over time (Fig. 2). When the two groups were compared against each other, however, the osteochondral group consistently underperformed. The day 42 values, for example, were $E_{Y}=87 \pm 12 \mathrm{kPa}$ and $\mathrm{GAG}=1.9 \pm 0.8 \% \mathrm{ww}$ for the osteochondral group compared to $E_{Y}=642 \pm 97$ and $G A G=4.6 \pm 1.4 \% \mathrm{ww}$ for the $\mathrm{Gel}$ group. Collagen values were not significantly different between the two groups. DNA quantification (not shown) indicated a $30 \%$ increase in cell number over the culture period with no significant differences between the two groups.

Live/dead staining revealed the presence of vital cells (98\% live and $2 \%$ dead) in all three regions of the osteochondral constructs, including the bone-only region where no cells were initially seeded (not shown). These cells most likely migrated from the periphery of the agarose region where they appeared to have attached to the underlying bony substrate and adopted an elongated morphology. Immunohistological staining indicated the continued deposition of type II collagen in all three regions (Fig. 3), suggesting that the chondrocyte phenotype was maintained, even with the change in morphology.

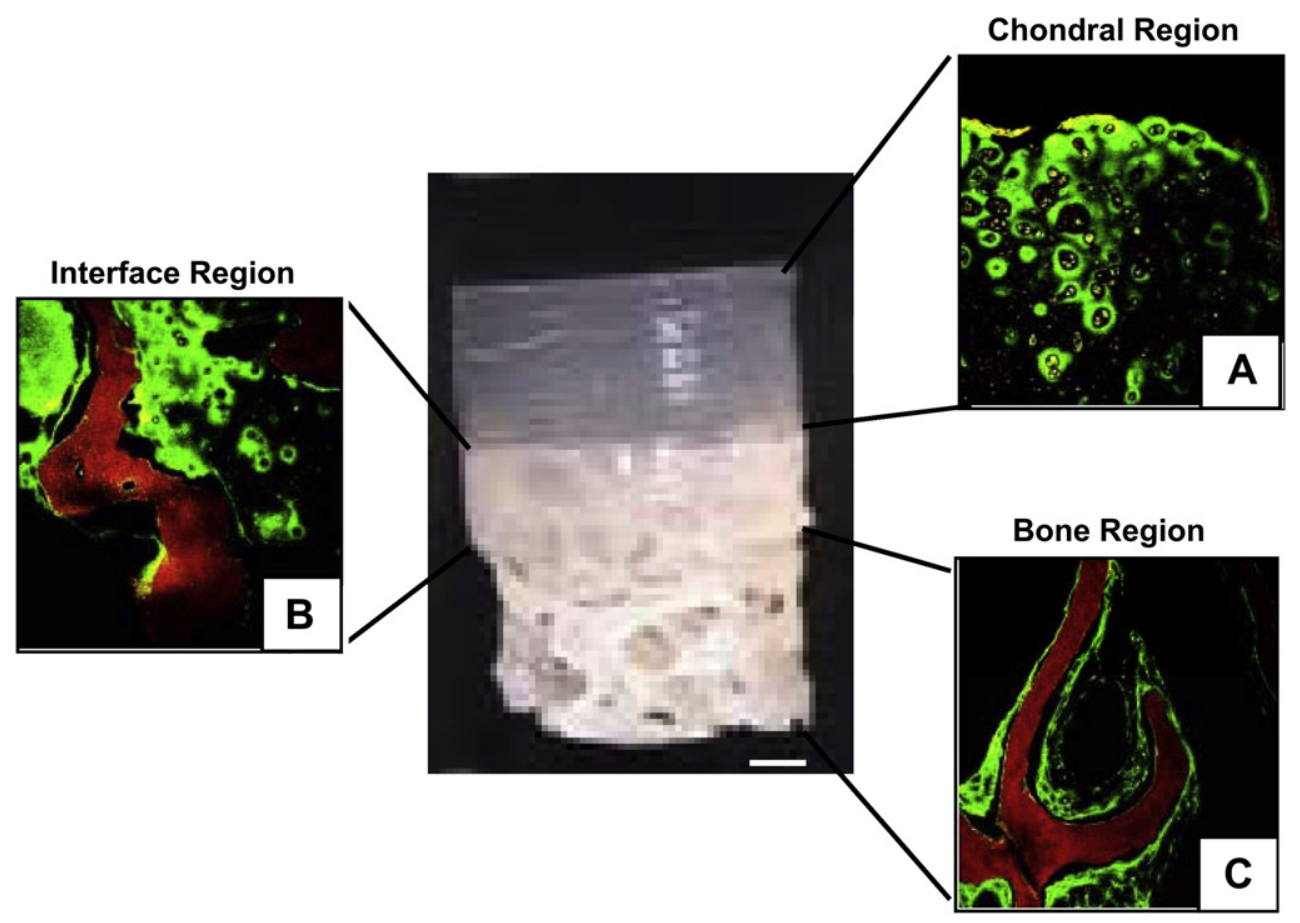

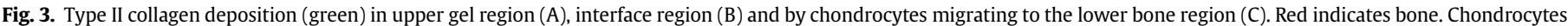
(grey) maintain phenotype in all three regions. Scale bar $=1 \mathrm{~mm}$. Magnification $=40 \times$. 
The presence of separate bone plugs in the co-culture experiments (Co-culture(bone)) resulted in significantly lower $E_{Y}$ and GAG by day 42 than the Gel groups and no statistical differences from the osteochondral group (Fig. 2). The demineralization of the bone $\mathrm{Co}-$ culture(demin) did not ameliorate these effects, yielding no statistical differences in $E_{Y}, G A G$, or collagen from the osteochondral groups and yielding statistically lower $E_{Y}$ and GAG than the $\mathrm{Gel}$ group (Fig. 2).

Constructs cultured without TGF- $\beta 3$ (No TGF) resulted in significantly lower $E_{Y}$ and GAG when compared to Gel groups, but higher $E_{Y}$ than the osteochondral group (Fig. 2). Histological staining indicated a well-distributed extracellular network in all groups (not shown). Von Kossa staining was negative for calcium accumulation in agarose constructs and, therefore, did not indicate an osteogenic phenotype (not shown).

\subsection{Study 2: delaying the introduction of bone to allow for extracellular development}

The addition of bone to the culture medium resulted in lower $E_{Y}$ values regardless of whether the bone was added later in culture (Fig. 4). The introduction of bone on day 14 resulted in an $E_{Y}$ that was $15 \%$ of the Gel group by day 28 and $25 \%$ of $\mathrm{Gel}$ by day 42 .
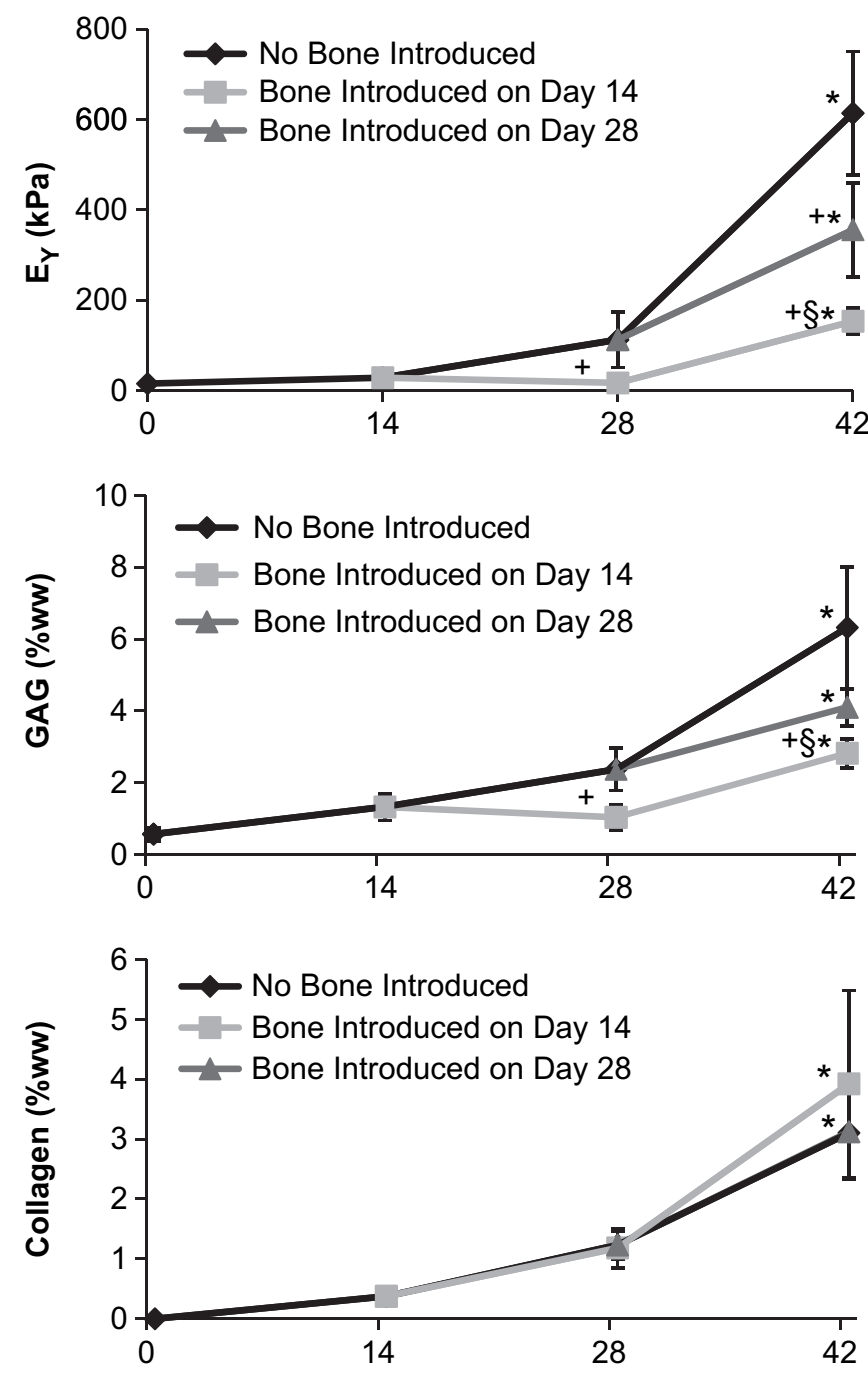

Fig. 4. Study 2: Co-culture of Gel with bone introduced to a subset of controls at different times in culture (either on day 14 or on day 28 ). ${ }^{*} p<0.05$ vs. previous time point. $+p<0.05$ vs. No Bone Introduced. $\S p<0.05$ Bone Introduced on day 14 vs. Bone Introduced on day 28. $n=10-12$ per group.
Likewise introduction of bone on day 28 resulted in $58 \%$ of the $E_{Y}$ of Gel group by day 42 . GAG values were similarly lower between the two bone groups and the Gel group, with the exception of the day 42 Bone Introduced on day 28 group vs. Gel. There were likewise no significant differences in collagen values between any of the groups.

\subsection{Study 3: generating osteochondral constructs using a porous tantalum base substrate}

By day 42, osteochondral groups formed with bone substrate (OC(Bone)) developed significantly lower $E_{Y}$ and GAG than Gel groups, as observed in the previous two studies (Fig. 5). Osteochondral constructs formed using a porous tantalum base, on the other hand, were not adversely affected by the scaffold and developed an $E_{\mathrm{Y}}$ of $730 \pm 65 \mathrm{kPa}$; a value within the range of native cartilage (500-1500 kPa) [16]. Gross morphology indicated a robust, cartilage-like chondral layer by day 42 in $O C$ (tantalum) specimens. The chondral region in $O C$ (bone) specimens appeared in some cases to have developed a gradient of extracellular deposition, becoming whiter and denser farther from the bony substrate. Unfortunately, there was some shrinkage in the histological preparation of the specimens of Study 3, nevertheless staining clearly indicated rich accumulation of proteoglycans in both the Gel and the $O C$ (tantalum) groups, with less intense staining in $O C$ (bone) groups. Shear testing (Fig. 6) showed that the integration strength of the chondral region to the tantalum base was greater than $200 \%$ that of the $O C$ (bone) groups whether it was expressed as peak load, stiffness, or Energy to Failure (only peak load shown). By comparison $O C$ (tantalum) groups developed $28 \%$ of the Energy to Failure observed in native osteochondral specimens (Fig. 6). All shear failure occurred along the interface between the gel region and bony substrate region of the osteochondral constructs.

\section{Discussion}

Taken together these results demonstrate that devitalized trabecular bone has an inhibitory effect on in vitro chondral tissue development when used as a base material for the tissue-engineering of osteochondral constructs for cartilage repair. There is no established level of mechanical competency that must be achieved to assure construct survival within the joint. Orthopedic surgeons have developed empirical guidelines for the transplantation of allogenic or autologous cartilage grafts with properties similar to the cartilage surrounding the defect, but there are no guidelines regarding the implantation of engineered cartilage tissues that have material properties less than native cartilage. Success using these tissues will likely depend on parameters such as the construct stiffness, defect size, and anatomic location, which together will determine the stress and strain on the implant. It is important to develop tissue-engineering protocols that result in stiffer, more functional tissues, as this will likely broaden their range of clinical applicability, possibly to include the tissue-engineering of total joint replacements (biological arthroplasty) [7,37,38]. Additionally, implantation of functional tissues with more mature elaborated matrix may better resist inflammatory cytokine-induced tissue degradation [16].

Our previous work has optimized culture conditions for growing engineered cartilage with material properties similar to native cartilage in less than 8 weeks [18]. For these chondral-only engineered tissues to be clinically relevant, however, they must be integrated with an underlying bony substrate that provides graft fixation upon implantation in a manner similar to native osteochondral grafts. As several weeks of culture are necessary for development of functional tissue properties, the scaffolds used in the construct design must foster tissue elaboration in long-term culture. In this context, devitalized trabecular bone initially seemed 

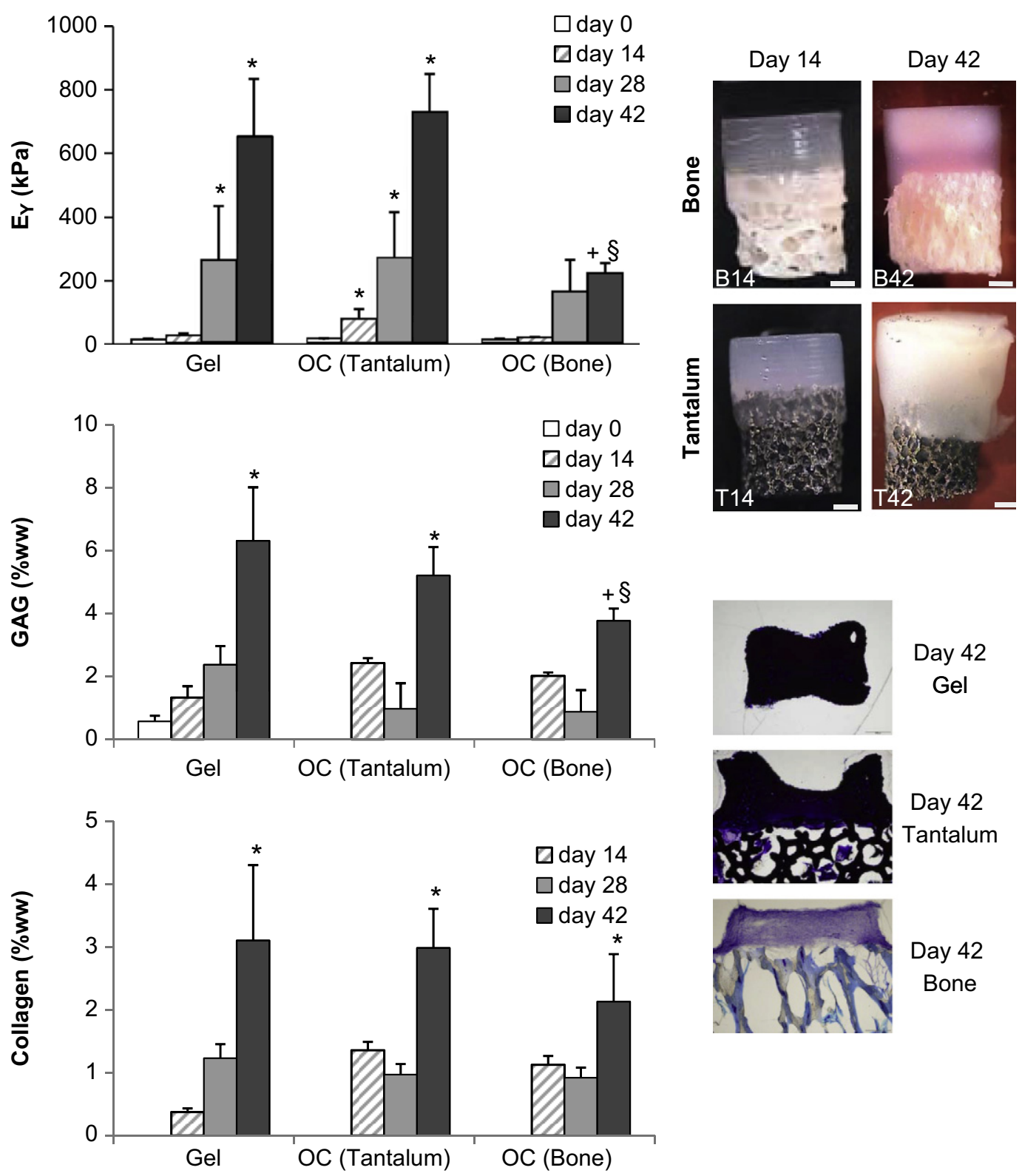

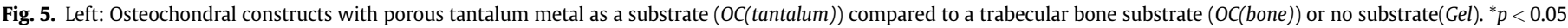

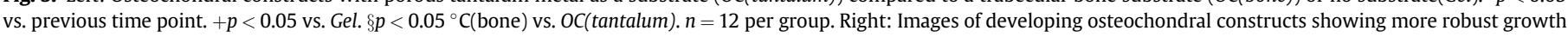

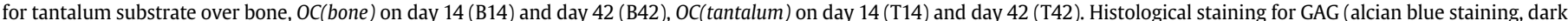

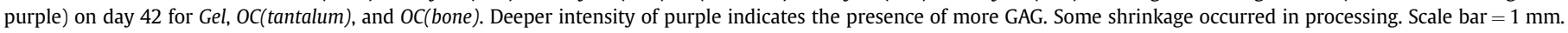

to be a promising choice for the engineering of osteochondral constructs [37,39-41]. We had anticipated few problems in its use as vital and devitalized bone are used clinically as a scaffold for bone repair [42-44]. Our findings showing the apparent inhibitory effect of bone on chondral development (Study 1) were, therefore, unexpected.

When faced with the results of Study 1, we initially hypothesized that the observed detrimental effects were a result of the methods in which we had cleaned and sterilized the freshly harvested bony substrates. This was not the case, however, as we tried two additional cleaning methods, including the use of industrially prepared bone tissue. None of these techniques led to significant improvements in the properties measured.

We had also speculated that the differences in the mechanical properties were not inherent to the tissues themselves, but an artifact of having porous substrate present during mechanical testing. This could be possible if, for example, compressive tests led to permanent deformation of the hydrogel into the porous bony substrate, or if small variations in the parallelism of the bony surfaces propagated into larger errors in the mechanical testing results. To account for this we tested constructs both on and off their bony substrates, but removing the bone prior to testing did not affect the results.

Thus the most likely remaining mechanisms in which bone was adversely affecting tissue development were as follows: (1) minerals and/or chemical factors associated with bone were leeching into the growth medium, (2) nutrient transport was limited by the presence of bone, or (3) TGF- $\beta 3$ was being sequestered away in the bone matrix and was, therefore, unavailable to cells.

The results of our co-culture experiment in Study 2 clearly indicated that excessive mineral content, or limitations on nutrients, or sequestering away of TGF- $\beta 3$, were not the main factors suppressing construct development. Cartilage constructs cocultured with devitalized bone matrix showed a decrease of 


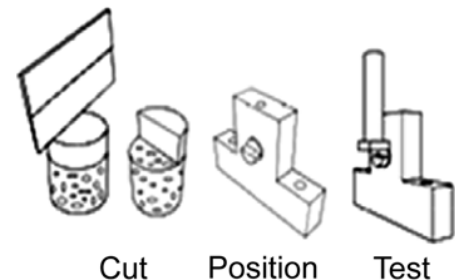

A
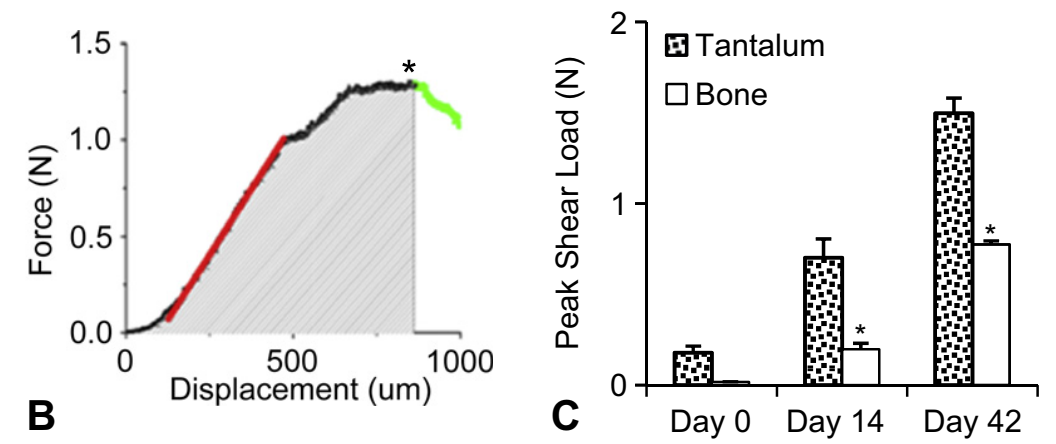

\begin{tabular}{|l|c|c|}
\hline Integration Strength Measurement & Day 42 Tantalum Group & Day 0 Native Cart \\
\hline Peak load $(\mathrm{N})$ & 1.40 .6 & 6.0 \\
\hline Stiffness $(\mathrm{N} / \mathrm{mm})$ & $2.9 \pm 12$ & $21.4 \pm 13.4$ \\
\hline Energy to Failure $\left(\mathrm{J} / \mathrm{m}^{2}\right)$ & $109 \pm 49$ & $386 \pm 123$ \\
\hline
\end{tabular}

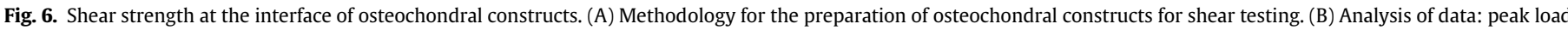

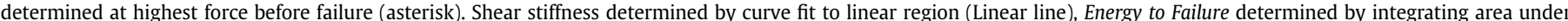

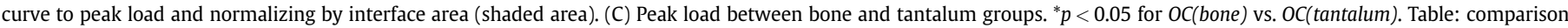
between tantalum group at day 42 and native cartilage.

mechanical properties and GAG levels. Similarly, constructs cultured in medium that had been preconditioned with bone (data not shown) also yielded significantly lower $E_{Y}$ than the Gel group. Collectively, our findings suggest that soluble chemical mediators were inhibiting the observed chondral tissue development. We speculate that osteoinductive factors released by bone may contribute to suppression of the chondrogenic phenotype [19]. Bone matrix is known to contain intrinsic cytokines and growth factors [45] that have a wide and largely unknown range of effects on cell development. The type and concentration of these factors vary even between the bones of the same animal [45,46]. Ongoing studies are aimed at elucidating the specific chemical factor(s).

In light of our observations of tissue maturation-independent deleterious effects of long-term culture with bone, one approach would be to cultivate the gel phase separately until maturation and then integrating this functional engineered chondral tissue to the bone with some fixation method such as sutures, glues or solders $[9,47,48]$ immediately prior to implantation. This approach has the advantage of allowing culture conditions to be optimized for each phase of the osteochondral construct, but precludes any cellmediated development of an interface between the two halves prior to implantation. However, the results of the current study do not support this approach as the addition of bone at later time points in culture resulted in poorer mechanical and biochemical properties when compared to bone-free controls.

The generation of osteochondral constructs was most successful when bone was substituted with a non-biological alternative. Using porous tantalum metal we were able to achieve native Young's modulus values and GAG and collagen content similar to chondralonly constructs. The integration strength (between the layers) of tantalum/agarose scaffolds was on par with, or exceeded, values reported in the literature $[29,49,50]$, but remained below native levels [30,51]. Improvements on the integration strength are likely to be achieved with improvements of the collagen content in the tissue, although currently there is no established level of integration strength required for tissue-engineered constructs to be successful in vivo.

In the context of creating functional engineered, osteochondral grafts with chondral regions that possess mechanical properties similar to native tissue and that are integrated to the underlying bony base via cell-elaborated matrix, porous tantalum metal appears to be a suitable bone substitute. Tantalum metal was chosen as a non-biological substrate control because of its current clinical application in orthopedic implants and its promise as an osteochondral scaffold for tissue-engineering [23-25]. An additional benefit of a tantalum base may be realized upon implantation since it may reduce direct contact with the underlying marrow and blood supply and, therefore, lessen the inflammatory effects associated with allogenic cells $[19,52,53]$. Tantalum metal has also been shown to be osteo- and chondroinductive [21-26] and may, therefore, promote integration between the two graft halves in culture as well as development of the subchondral plate after implantation. Agarose hydrogel has been used extensively in cartilage biology and in tissue-engineering efforts for maintaining long-term chondrocyte suspension cultures [54-57]. It is currently being explored as a scaffold component of a next generation autologous cartilage implantation $(\mathrm{ACI})$ procedure called Cartipatch [58] where it is currently being tested in phase III clinical trials [59]. In this context, our findings support the use of a biohybrid osteochondral graft design comprised of a cell-seeded hydrogel and underlying tantalum metal substrate for promoting functional development of tissue-engineered osteochondral constructs in long-term culture. If an appropriate human cell source is identified (e.g., allogenic or autologous chondrocytes, stem cells, etc.), we anticipate the possibility for immediate clinical application of the agarose-tantalum biohybrid system.

\section{Conclusions}

In the current study, devitalized trabecular bone had an inhibitory effect on in vitro chondral tissue development when used as a base material for the tissue-engineering of osteochondral constructs for cartilage repair. Changes in the method of bone preparation or the timing of its introduction did not ameliorate the effects. In contrast, osteochondral constructs with native cartilage properties were achieved when a porous tantalum metal base material was adopted instead of bone. This work suggests that devitalized bone may not be a suitable substrate for long-term cultivation of osteochondral grafts.

\section{Acknowledgments}

This research was funded by the following grants: National Institutes for Health grants: R01 AR46568, R21 AR53530, P41EB002520, and R01 DE16525. 
Musculoskeletal Transplant Foundation grant: CU07-194.

Dr. Sonny Bal has received financial support from Zimmer unrelated to the current project.

\section{References}

[1] Hangody L, Modis L. Surgical treatment options for weight bearing articular surface defect. Orv Hetil 2006;147(46):2203-12.

[2] Hangody L, Feczko P, Bartha L, Bodo G, Kish G. Mosaicplasty for the treatment of articular defects of the knee and ankle. Clin Orthop Relat Res 2001;(391 Suppl.):S328-36.

[3] Hangody L, Fules P. Autologous osteochondral mosaicplasty for the treatment of full-thickness defects of weight-bearing joints: ten years of experimental and clinical experience. J Bone Joint Surg Am 2003;85-A(Suppl. 2):25-32.

[4] Marcacci M, Kon E, Zaffagnini S, Iacono F, Neri MP, Vascellari A, et al. Multiple osteochondral arthroscopic grafting (mosaicplasty) for cartilage defects of the knee: prospective study results at 2-year follow-up. Arthroscopy 2005;21(4): 462-70.

[5] Williams 3rd RJ, Ranawat AS, Potter HG, Carter T, Warren RF. Fresh stored allografts for the treatment of osteochondral defects of the knee. J Bone Joint Surg Am 2007;89(4):718-26.

[6] Jiang CC, Chiang H, Liao CJ, Lin YJ, Kuo TF, Shieh CS, et al. Repair of porcine articular cartilage defect with a biphasic osteochondral composite. J Orthop Res 2007;25(10):1277-90.

[7] Schek RM, Taboas JM, Hollister SJ, Krebsbach PH. Tissue engineering osteochondral implants for temporomandibular joint repair. Orthod Craniofac Res 2005;8(4):313-9.

[8] Tuli R, Nandi S, Li WJ, Tuli S, Huang X, Manner PA, et al. Human mesenchyma progenitor cell-based tissue engineering of a single-unit osteochondral construct. Tissue Eng 2004;10(7-8):1169-79.

[9] Schaefer D, Martin I, Shastri P, Padera RF, Langer R, Freed LE, et al. In vitro generation of osteochondral composites. Biomaterials 2000;21(24): 2599-606.

[10] Orr TE, Patel AM, Wong B, Hatzigiannis GP, Minas T, Spector M. Attachment of periosteal grafts to articular cartilage with fibrin sealant. J Biomed Mater Res 1999;44(3):308-13.

[11] Dennis JE, Caplan AI. Porous ceramic vehicles for rat-marrow-derived (Rattus norvegicus) osteogenic cell delivery: effects of pre-treatment with fibronectin or laminin. J Oral Implantol 1993;19(2):106-15 [discussion 36-7].

[12] Kawamura S, Wakitani S, Kimura T, Maeda A, Caplan AI, Shino K, et al. Articular cartilage repair. Rabbit experiments with a collagen gel-biomatrix and chondrocytes cultured in it. Acta Orthop Scand 1998;69(1):56-62.

[13] Wakitani S, Goto T, Young RG, Mansour JM, Goldberg VM, Caplan AI. Repair of large full-thickness articular cartilage defects with allograft articular chondrocytes embedded in a collagen gel. Tissue Eng 1998;4(4):429-44.

[14] Caplan AI, Elyaderani M, Mochizuki Y, Wakitani S, Goldberg VM. Principles of cartilage repair and regeneration. Clin Orthop 1997;342:254-69.

[15] Gao J, Dennis JE, Solchaga LA, Goldberg VM, Caplan AI. Repair of osteochondral defect with tissue-engineered two-phase composite material of injectable calcium phosphate and hyaluronan sponge. Tissue Eng 2002;8(5):827-37.

[16] Lima EG, Tan AR, Tai T, Bian L, Stoker AM, Ateshian GA, et al. Differences in interleukin-1 response between engineered and native cartilage. Tissue Eng 2008.

[17] Duda GN, Maldonado ZM, Klein P, Heller MO, Burns J, Bail H. On the influence of mechanical conditions in osteochondral defect healing. J Biomech 2005;38(4):843-51.

[18] Lima EG, Bian L, Ng KW, Mauck RL, Byers BA, Tuan RS, et al. The beneficial effect of delayed compressive loading on tissue-engineered cartilage constructs cultured with tgf-beta3. Osteoarthr Cartil 2007;15(9):1025-33.

[19] Urist MR. Bone: formation by autoinduction. Science 1965;150(698):893-9.

[20] Lima EG, Mauck RL, Gasinu S, Ateshian GA, Hung CT. Functional tissue engineering of free-swelling and dynamically loaded osteochondral constructs. San Francisco, California: Orthopaedic Research Society; 2004.

[21] Wigfield C, Robertson J, Gill S, Nelson R. Clinical experience with porous tantalum cervical interbody implants in a prospective randomized controlled trial. Br J Neurosurg 2003;17(5):418-25.

[22] Mardones RM, Reinholz GG, Fitzsimmons JS, Zobitz ME, An KN, Lewallen DG et al. Development of a biologic prosthetic composite for cartilage repair. Tissue Eng 2005;11(9-10):1368-78.

[23] Bobyn JD, Toh KK, Hacking SA, Tanzer M, Krygier JJ. Tissue response to porous tantalum acetabular cups: a canine model. J Arthroplasty 1999;14(3):347-54

[24] Levine B, Sporer S, Della Valle CJ, Jacobs JJ, Paprosky W. Porous tantalum in reconstructive surgery of the knee: a review. J Knee Surg 2007;20(3):185-94.

[25] Christie MJ. Clinical applications of trabecular metal. Am J Orthop 2002;31(4):219-20.

[26] Hacking SA, Bobyn JD, Toh K, Tanzer M, Krygier JJ. Fibrous tissue ingrowth and attachment to porous tantalum. J Biomed Mater Res 2000;52(4):631-8.

[27] Deglurkar M, Davy DT, Stewart M, Goldberg VM, Welter JF. Evaluation of machining methods for trabecular metal implants in a rabbit intramedullary osseointegration model. J Biomed Mater Res B Appl Biomater 2007;80(2): 528-40.

[28] Soltz MA, Ateshian GA. Experimental verification and theoretical prediction of cartilage interstitial fluid pressurization at an impermeable contact interface in confined compression. J Biomech 1998;31(10):927-34.
[29] Allan KS, Pilliar RM, Wang J, Grynpas MD, Kandel RA. Formation of biphasic constructs containing cartilage with a calcified zone interface. Tissue Eng 2007;13(1):167-77.

[30] Broom ND, Oloyede A, Flachsmann R, Hows M. Dynamic fracture characteristics of the osteochondral junction undergoing shear deformation. Med Eng Phys 1996;18(5):396-404.

[31] Kelly TA, Ng KW, Wang CC, Ateshian GA, Hung CT. Spatial and temporal development of chondrocyte-seeded agarose constructs in free-swelling and dynamically loaded cultures. J Biomech 2005.

[32] Farndale RW, Sayers CA, Barrett AJ. A direct spectrophotometric microassay for sulfated glycosaminoglycans in cartilage cultures. Connect Tissue Res 1982;9(4):247-8.

[33] Stegemann H, Stalder K. Determination of hydroxyproline. Clin Chim Acta $1967 ; 18(2): 267-73$

[34] Vunjak-Novakovic G, Martin I, Obradovic B, Treppo S, Grodzinsky AJ, Langer R, et al. Bioreactor cultivation conditions modulate the composition and mechanical properties of tissue-engineered cartilage. J Orthop Res 1999;17(1):130-8.

[35] Lin W, Shuster S, Maibach HI, Stern R. Patterns of hyaluronan staining are modified by fixation techniques. J Histochem Cytochem 1997;45(8):1157-63.

[36] Kelly TA, Fisher MB, Oswald ES, Tai T, Mauck RL, Ateshian GA, et al. Low-serum media and dynamic deformational loading in tissue engineering of articular cartilage. Ann Biomed Eng 2008.

[37] Hung CT, Lima EG, Mauck RL, Takai E, LeRoux MA, Lu HH, et al. Anatomically shaped osteochondral constructs for articular cartilage repair. J Biomech 2003;36(12):1853-64.

[38] Ateshian GA, Hung CT. Patellofemoral joint biomechanics and tissue engineering. Clin Orthop Relat Res 2005;436:81-90.

[39] Lima EG, Mauck RL, Han SH, Park S, Ng KW, Ateshian GA, et al. Functional tissue engineering of chondral and osteochondral constructs. Biorheology 2004;41(3-4):577-90.

[40] Hung CT, Mauck RL, Wang CC, Lima EG, Ateshian GA. A paradigm for functional tissue engineering of articular cartilage via applied physiologic deformational loading. Ann Biomed Eng 2004;32(1):35-49.

[41] Tognana E, Chen F, Padera RF, Leddy HA, Christensen SE, Guilak F, et al. Adjacent tissues (cartilage, bone) affect the functional integration of engineered calf cartilage in vitro. Osteoarthr Cartil 2005;13(2):129-38.

[42] Mulliken JB, Glowacki J, Kaban LB, Folkman J, Murray JE. Use of demineralized allogeneic bone implants for the correction of maxillocraniofacial deformities. Ann Surg 1981;194(3):366-72.

[43] Ellegaard B, Karring T, Loe $H$. The fate of vital and devitalized bone grafts in the healing of interradicular lesions. J Periodontal Res 1975;10(2):88-97.

[44] Dallari D, Fini M, Stagni C, Torricelli P, Nicoli Aldini N, Giavaresi G, et al. In vivo study on the healing of bone defects treated with bone marrow stromal cells, platelet rich plasma and freeze-dried bone allografts, alone and in combination. J Orthop Res 2005.

[45] Gao J, Knaack D, Goldberg VM, Caplan AI. Osteochondral defect repair by demineralized cortical bone matrix. Clin Orthop Relat Res 2004;(427 Suppl.):S62-6.

[46] Urist MR, Jurist Jr JM, Dubuc FL, Strates BS. Quantitation of new bone formation in intramuscular implants of bone matrix in rabbits. Clin Orthop Relat Res 1970;68:279-93.

[47] Schaefer D, Martin I, Jundt G, Seidel J, Heberer M, Grodzinsky A, et al. Tissueengineered composites for the repair of large osteochondral defects. Arthritis Rheum 2002;46(9):2524-34.

[48] Sherwood JK, Riley SL, Palazzolo R, Brown SC, Monkhouse DC, Coates M, et al. A three-dimensional osteochondral composite scaffold for articular cartilage repair. Biomaterials 2002;23(24):4739-51.

[49] Tam HK, Srivastava A, Colwell Jr CW, D'Lima DD. In vitro model of full-thickness cartilage defect healing. J Orthop Res 2007;25(9):1136-44.

[50] Nettles DL, Vail TP, Morgan MT, Grinstaff MW, Setton LA. Photocrosslinkable hyaluronan as a scaffold for articular cartilage repair. Ann Biomed Eng 2004:32(3):391-7.

[51] Kumar P, Oka M, Nakamura T, Yamamuro T, Delecrin J. Mechanical strength of osteochondral junction. Nippon Seikeigeka Gakkai Zasshi 1991;65(11):1070-7.

[52] Sun L, Hu Y, Ning Z. Immunological comparison of differently treated allografts of bone. Zhonghua Wai Ke Za Zhi. [Chinese Journal of Surgery] 1996; 34(8):460-3.

[53] Sun L, Hu Y, Ning Z, Liang Z. The correlation between immune rejection and osteoinduction of allogeneic bone grafting. Chin Med J 1998;111(9):818-22.

[54] Buschmann MD, Gluzband YA, Grodzinsky AJ, Kimura JH, Hunziker EB. Chondrocytes in agarose culture synthesize a mechanically functional extracellular matrix. J Orthop Res 1992;10(6):745-58.

[55] Benya PD, Shaffer JD. Dedifferentiated chondrocytes reexpress the differentiated collagen phenotype when cultured in agarose gels. Cell 1982;30(1):215-24.

[56] Mauck RL, Soltz MA, Wang CC, Wong DD, Chao PH, Valhmu WB, et al. Functional tissue engineering of articular cartilage through dynamic loading of chondrocyte-seeded agarose gels. J Biomech Eng 2000;122(3):252-60.

[57] Mauck RL, Wang CC, Oswald ES, Ateshian GA, Hung CT. The role of cell seeding density and nutrient supply for articular cartilage tissue engineering with deformational loading. Osteoarthr Cartil 2003;11(12):879-90 [OARS, Osteoarthritis Research Society]

[58] Selmi TA, Verdonk P, Chambat P, Dubrana F, Potel JF, Barnouin L, et al. Autologous chondrocyte implantation in a novel alginate-agarose hydrogel: outcome at two years. J Bone Joint Surg Br 2008;90(5):597-604.

[59] Trials N. Multicenter randomized trial comparing cartipatch ${ }^{\mathrm{TM}}$ versus mosaicoplasty. 2008 